\title{
Preoperative erectile function and the pathologic features of prostate cancer
}

\author{
Chang Wook Jeong ${ }^{1,2}$, Sangchul Lee ${ }^{1,2}$, Seong Jin Jeong ${ }^{1,2}$, Sung Kyu Hong ${ }^{1,2}$, Seok-Soo Byun ${ }^{1,2}$, \\ Sang Eun Lee 1,2 \\ ${ }^{1}$ Department of Urology, Seoul National University Bundang Hospital, Seongnam, Korea; ${ }^{2}$ Department \\ of Urology, College of Medicine, Seoul National University, Seoul, Korea
}

\section{ABSTRACT}

Purpose: We evaluated whether preoperative erectile function is associated with pathologic features in the patients who underwent radical prostatectomy (RP).

Materials and Methods: We reviewed medical records of 1,743 men who underwent RP from November 2003 through May 2012. Of these, 50 patients who had prior hormone therapy and 272 patients who had lacking data of International Index of Erectile Function-5 (IIEF-5) were excluded. Men whose IIEF-5 was in the lower 25 percentile were assigned as Low Erectile Function group and the others were assigned as Control group. We compared pathologic features using univariable and multivariable logistic regression analysis between two groups.

Results: A total of 1,421 patients were included in the analysis. Patients' age was 65.8 \pm 6.7 years and prostate-specific antigen (PSA) was $12.8 \pm 16.1 \mathrm{ng} / \mathrm{mL}$. Median and low 25 percentile of IIEF-5 were 14 and 8, respectively. Low Erectile Function group (IIEF-5<8) had higher risk to have high Gleason score $(\geq 7(4+3)$, odds ratio (OR) 1.642, $\mathrm{p}<0.001)$ and large tumor volume ( $\geq 5 \mathrm{~mL}, \mathrm{OR} 1.292, \mathrm{p}=0.042)$. Even after adjusting age, year of surgery, body mass index, Charlson comorbidity index, PSA, clinical stage and biopsy Gleason score, Low Erectile Function group still had higher risk of high Gleason score (OR 1.910, $\mathrm{p}<0.001$ ) and large tumor volume (OR 1.390, $\mathrm{p}=0.04$ ) by multivariable logistic regressions.

Conclusions: Lower erectile function before RP was associated with higher Gleason's score and larger tumor volume in final pathology. Thus, erectile function could be a surrogate barometer for prostate cancer aggressiveness.

\section{ARTICLE INFO}

\section{Key words:}

Prostatic neoplasms, erectile

function, pathology

Int Braz J Urol. 2015; 41: 265-73

Submitted for publication:

December 19, 2013

Accepted after revision:

June 08, 2014

\section{INTRODUCTION}

Prostate cancer (PC) is the second common cancer diagnosed and represents the sixth leading cause of death in male cancer patients worldwide (1). PC incidence rates increase in nearly all countries except in a few high-income regions. At present, any kind of radical prostatectomy (RP) is the most commonly used treatment modality for localized PC. However, there is concern about adverse pathologic outcome after RP because of heterogeneous nature of PC. With proper estimation of final pathology, some patients can choose active surveillance or radiation therapy instead of RP (2). Some patients can expect adjuvant or salvage treatment after RP (3).

Erectile dysfunction (ED) is one of the most common side effects and major reason of decrea- 
sed quality of life during and after various types of treatment for PC (4-6). Preoperative erectile function is a very important predictor after PC treatment (4). Preoperative ED is also associated with various medical conditions such as obesity, hyperlipidemia, diabetes mellitus (DM), and metabolic syndrome $(7,8)$. ED is a multifactorial phenomenon associated with these medical conditions. Thus degree of ED may correlate with affected number and degree of these medical conditions. Furthermore, there have been some reports that many of these medical conditions are related to adverse pathologic features of PC (9-11). Consequently, decreased erectile function before RP could serve as a barometer for adverse pathologic outcomes. However, this correlation is not fully understood. Thus, we evaluated whether preoperative erectile function is associated with pathologic features in patients who underwent RP.

\section{MATERIALS AND METHODS}

The study was approved by the Institutional Review Board (IRB) of Seoul National University Bundang Hospital (Seongnam, Republic of Korea). The IRB number is B-1301/186-105.

\section{PATIENTS}

We collected the data from a prospectively registered database of an RP cohort in our institution. A total of 1,743 consecutive patients who underwent RP from November 2003 through May 2012 were evaluated. Among them, 50 patients who had prior hormone therapy and 272 patients who lacked data for the International Index of Erectile Function-5 (IIEF-5) were excluded. Thus, a total of 1,421 cases were included in the analysis. Men whose IIEF-5 was in the lower 25th percentile were assigned to the Low Erectile Function (LEF) group, and the others were assigned to the Control group. The $25^{\text {th }}$ percentile was the predetermined discrimination point before analysis to evade bias.

\section{PATHOLOGIC EXAMINATION}

One experienced genitourinary pathologist (G. C) processed and examined all surgical spe- cimens. Specimen handling and reporting followed the internationally standardized protocols $(12,13)$. The pathologic stage was evaluated based on the sixth edition of the American Joint Cancer Committee Cancer staging criteria. The prostate was sectioned into 4-mm slices as the protocol. The positive surgical margin was recorded if cancer was involved at the inked surface. Tumor volume was routinely measured using the grid method.

\section{Statistical analysis}

Clinicopathologic variables, including pathologic stage, Gleason's score and tumor volume, were compared between LEF and Control group using either Student t-test or chi-square test. Clinical factors including erectile function group were evaluated to associate with adverse pathologic features by means of univariate and multivariate logistic regression analyses. Tested adverse pathologic outcomes were high Gleason's score $(\geq 7(4+3)$ and tumor volume ( $>5 \mathrm{~mL}$ ). Evaluated clinical factors were age, body mass index (BMI), year of surgery, Charlson comorbidity index (CCI; 0 vs. 1 vs. $\geq 2$ ), pre-biopsy prostate-specific antigen (PSA), clinical stage (T1 vs. T2 vs. T3), biopsy Gleason' score ( $\leq 6$ vs. 7 vs. $\geq 8$ ), as well as erectile function group (Control vs. LEF group). All statistical analyses were performed using IBM SPSS Statistics 20.0 (IBM Corporation, Armonk, $\mathrm{NY}$ ). For all statistical comparisons, a $\mathrm{p}$ value $<0.05$ (2-sided) was considered significant.

\section{RESULTS}

The basic characteristics of the 1,421 patients stratified by erectile function are presented in Table-1. The patients' age was $65.8 \pm 6.7$ years, and the PSA was $12.8 \pm 16.1 \mathrm{ng} / \mathrm{mL}$. The median and lower 25th percentile of the IIEF-5 were 14 and 8, respectively. A total of 346 (24.3\%) patients were assigned to the LEF group (IIEF-5<8), and the remaining 1075 (75.5\%) were assigned to the Control group (IIEF-5 $\geq 8$ ). As expected, the LEF group showed an older age $(p<0.001)$, higher prevalence of DM $(p<0.001)$, and higher CCI $(p<0.001)(T a-$ ble-1). The clinicopathologic features of the LEF group more often included poorly differentiated pathology in both the pre-surgical $(p<0.001)$ and 
Table- 1 - Patient demographics and clinical characteristics stratified by erectile function ( $<25$ percentile, IIEF- $5<8$ vs. $\geq 25$ percentile, IIEF-5 $\geq 8$ ).

\begin{tabular}{|c|c|c|c|}
\hline Variables & $\begin{array}{l}\text { Low Erectile Function } \\
\text { group }(\mathrm{n}=346)\end{array}$ & Control group ( $n=1075$ ) & $p$ value \\
\hline Age (years) & $69.16 \pm 5.18$ & $64.69 \pm 6.80$ & $<0.001$ \\
\hline Body mass index (kg/m²) & $24.09 \pm 2.74$ & $24.42 \pm 2.57$ & 0.820 \\
\hline Diabetes mellitus (\%) & $74(21.4)$ & $138(12.8)$ & $<0.001$ \\
\hline Charson comorbidity index (\%) & & & $<0.001$ \\
\hline 0 & $240(69.4)$ & $893(83.1)$ & \\
\hline 1 & $96(27.7)$ & $172(16.0)$ & \\
\hline$\geq 2$ & $10(2.9)$ & $10(0.9)$ & \\
\hline PSA (ng/mL) & $12.31 \pm 12.65$ & $12.94 \pm 17.07$ & 0.780 \\
\hline Clinical stage (\%) & & & 0.703 \\
\hline$\leq \mathrm{T} 1 \mathrm{c}$ & $227(65.6)$ & $688(64.0)$ & \\
\hline$\geq \mathrm{T} 2 \mathrm{a}$ & $119(34.6)$ & $387(36.0)$ & \\
\hline Gleason's score, biopsy (\%) & & & $<0.001$ \\
\hline$\leq 6$ & $166(48.1)$ & $535(50.4)$ & \\
\hline 7 & $126(36.5)$ & $381(35.9)$ & \\
\hline$\geq 8$ & $53(15.4)$ & $146(13.7)$ & \\
\hline Prostate volume (mL) & $38.07 \pm 16.66$ & $38.02 \pm 15.79$ & 0.900 \\
\hline Operation time (min) & $151.88 \pm 43.05$ & $157.59 \pm 45.95$ & 0.550 \\
\hline $\mathrm{EBL}(\mathrm{mL})$ & $331.72 \pm 356.19$ & $362.25 \pm 417.59$ & 0.223 \\
\hline Pathologic stage (\%) & & & 0.277 \\
\hline$\leq \mathrm{T} 2 \mathrm{c}$ & $225(65.1)$ & $740(68.9)$ & \\
\hline$\geq T 3 a$ & $121(34.9)$ & $335(31.1)$ & \\
\hline Gleason's score, pathologic (\%) & & & 0.007 \\
\hline$\leq 6$ & $42(12.1)$ & $199(18.5)$ & \\
\hline 7 & $256(74.0)$ & $768(71.4)$ & \\
\hline$\geq 8$ & $48(13.9)$ & $108(10.0)$ & \\
\hline Tumor volume (mL) & $12.52 \pm 112.85$ & $6.57 \pm 17.94$ & 0.048 \\
\hline
\end{tabular}

final pathologies $(\mathrm{p}=0.007)$ compared to the Control group. Furthermore, the LEF group had a larger tumor volume than the Control group ( $\mathrm{p}=0.048$ ).

The LEF group had a higher risk of a high Gleason score $(\geq 7(4+3)$, odds ratio (OR) 1.642,
95\% confidence interval (CI) 1.281-2.106, $\mathrm{p}<0.001)$ and large tumor volume ( $\geq 5 \mathrm{~mL}$, OR 1.292, 95\% CI 1.010-1.654, $\mathrm{p}=0.042$ ). Even after adjusting for age, year of surgery, BMI, CCI, PSA, clinical stage, and biopsy Gleason score, the LEF group still had 
a higher risk of a high Gleason score (OR 1.910, 95\% CI 1.348-2.705, $p<0.001)$ and large tumor volume (OR 1.390,95\% CI $1.015-1.900, \mathrm{p}=0.04$ ) by multivariate logistic regression (Tables 2 and 3).

\section{DISCUSSION}

ED is a common disorder that affects men older than 40 years of age (8). Like a PC statistics, prevalence of ED increases exponentially by age after 50 years of age, even though worldwide basis shows a wide variation. ED increases to $20-40 \%$ in men aged between 60 to 69 years, $50-100 \%$ in men in their 70s and 80s (14). In case of the United States white men, the latent PC was found in 37\%, $44 \%, 65 \%$ and $83 \%$ of the autopsy cases in the fifth, sixth, seventh, and eighth decades of age, respectively (15). Furthermore, the proportion of significant PC also exponentially increased with age after 60s and thereafter (16).

The etiology of ED could be classified as psychogenic, organic, or their combination. The organic causes are neurogenic, hormonal, arterial, cavernosal, and etc. ED is also associated with various medical conditions such as diabetes mellitus, hyperlipidemia, higher BMI or obesity, and consequently metabolic syndrome (8). Cardiovascular disease, in particular coronary artery disease is a strong risk factor for ED, too. ED was confirmed to be associated with significant increase in future cardiac events $(17,18)$. The evidence indicates that the etiology of ED is multifactorial, and ED is also associated with many systemic diseases.

However, some systemic conditions associated with ED have been revealed having correlation with negative oncologic outcome in PC. Higher BMI was associated with an increased tumor volume (9), higher Gleason grade, positive surgical margins, and early biochemical progression after RP (19). Our group also studied the association between obesity and pathological outcomes after $\mathrm{RP}$ in Korean men (11). We found that higher BMI was significantly associated with extraprostatic extension $(p=0.014)$ and positive surgical margin

Table-2 - Univariate and multivariate logistic regression analysis to predict high Gleason's score $(\geq 7[4+3])$.

\begin{tabular}{|c|c|c|c|c|}
\hline \multirow[t]{2}{*}{ Variables } & \multicolumn{2}{|c|}{ Univariate analysis } & \multicolumn{2}{|c|}{ Multivariate analysis } \\
\hline & Odds ratio $(95 \% \mathrm{Cl})$ & $p$ value & Odds ratio $(95 \% \mathrm{Cl})$ & $p$ value \\
\hline IIEF-5<8 & $1.642(1.281-2.106)$ & $<0.001$ & $1.910(1.348-2.705)$ & $<0.001$ \\
\hline Age (years) & $1.046(1.028-1.064)$ & $<0.001$ & $1.016(0.992-1.040)$ & 0.195 \\
\hline Body mass index $\left(\mathrm{kg} / \mathrm{m}^{2}\right)$ & 1.026 ( 0.984- .070) & 0.226 & 1.055 ( 0.997-1.115) & 0.064 \\
\hline Year of surgery & 1.155 ( $1.098-1.215)$ & $<0.001$ & $1.156(1.082-1.236)$ & $<0.001$ \\
\hline Charlson comorbidity index & & 0.652 & & 0.932 \\
\hline 1 vs. 0 & $1.124(0.852-1.484)$ & 0.407 & $1.057(0.727-1.536)$ & 0.771 \\
\hline$\geq 2$ vs. 0 & $0.836(0.319-2.192)$ & 0.716 & $1.184(0.329-4.260)$ & 0.796 \\
\hline LogPSA (ng/mL) & $17.208(11.469-25.820)$ & $<0.001$ & $6.212(3.811-10.127)$ & $<0.001$ \\
\hline Clinical Stage & & $<0.001$ & & 0.065 \\
\hline T2 vs. T1 & 2.133 ( $1.699-2.678)$ & $<0.001$ & $1.444(1.062-1.966)$ & 0.019 \\
\hline T3 vs. T1 & $>100$ & - & $>100$ & - \\
\hline Biopsy Gleason's score & & $<0.001$ & & $<0.001$ \\
\hline $7 \mathrm{vs} \leq 6$ & $8.387(6.156-11.426)$ & $<0.001$ & $6.768(4.865-9.414)$ & $<0.001$ \\
\hline$\geq 8$ vs. $\leq 6$ & 98.390 ( 56.907-170.112 ) & $<0.001$ & $71.329(40.049-127.039)$ & $<0.001$ \\
\hline
\end{tabular}


Table-3 - Univariate and multivariate logistic regression analysis to larger tumor volume (>5 mL).

\begin{tabular}{|c|c|c|c|c|}
\hline \multirow[t]{2}{*}{ Variables } & \multicolumn{2}{|c|}{ Univariate analysis } & \multicolumn{2}{|c|}{ Multivariate analysis } \\
\hline & Odds ratio $(95 \% \mathrm{Cl})$ & $p$ value & Odds ratio $(95 \% \mathrm{Cl})$ & $p$ value \\
\hline IIIEF-5<8 & 1.292 ( $1.010-1.654)$ & 0.042 & $1.390(1.015-1.900)$ & 0.040 \\
\hline Age (years) & 1.029 ( $1.013-1.046)$ & 0.001 & 1.015 ( 0.993-1.036) & 0.177 \\
\hline Body mass index (kg/m²) & 1.038 ( 0.996-1.082) & 0.073 & 1.066 ( $1.014-1.122)$ & 0.012 \\
\hline Year of surgery & $0.942(0.898-0.988)$ & 0.014 & $0.858(0.809-0.910)$ & $<0.001$ \\
\hline Charlson comorbidity index & & 0.233 & & 0.844 \\
\hline 1 vs. 0 & 0.922 ( 0.699-1.214) & 0.562 & 0.930 ( 0.664-1.301) & 0.930 \\
\hline$\geq 2$ vs. 0 & $0.400(0.133-1.203)$ & 0.103 & $0.765(0.222-2.630)$ & 0.765 \\
\hline LogPSA (ng/mL) & 47.590 ( 29.778-76.057) & $<0.001$ & 31.068 ( 18.842-51.228) & $<0.001$ \\
\hline Clinical Stage & & $<0.001$ & & 0.040 \\
\hline T2 vs. T1 & 2.156 ( 1.723-2.697 ) & $<0.001$ & $1.420(1.081-1.865)$ & 0.012 \\
\hline T3 vs. T1 & 8.797 ( 0.979-79.059) & 0.052 & $1.838(0.074-45.930)$ & 0.711 \\
\hline Biopsy Gleason’s score & & $<0.001$ & & $<0.001$ \\
\hline 7 vs. $\leq 6$ & $3.197(2.488-4.108)$ & $<0.001$ & $2.040(1.534-2.711)$ & $<0.001$ \\
\hline$\geq 8$ vs. $\leq 6$ & 8.855 ( 6.210-12.626) & $<0.001$ & 4.437 ( $2.945-6.685$ ) & $<0.001$ \\
\hline
\end{tabular}

$(p=0.019)$ only after multivariate-adjusting not in univariate analysis. In the present study, BMI was shown to have positive trend in higher Gleason's score and larger tumor volume without significance. When adjusting other variable, BMI was significantly associated with larger tumor volume (OR 1.066, 95\% CI 1.014-1.122, $\mathrm{p}=0.012$ ). Compared with observations from a Western cohort, this association might not be prominent. We suggest that this disparity may be due to Korean men being generally leaner than their Western counterparts. Mean BMI of our cohort was $24.3 \mathrm{~kg} / \mathrm{m}^{2}$ and obese men $\left(\mathrm{BMI} \geq 30 \mathrm{~kg} / \mathrm{m}^{2}\right)$ only accounted for $2.2 \%$ $(31 / 1,421)$.

Interestingly, several pieces of evidence have indicated that patients with DM are at decreased risk for the development of PC, which is contrary to other malignancies (20). A meta-analysis of 19 cohort or case-control study showed protective effect of DM for developing PC (relative risk (RR) 0.84, 95\% CI 0.76-0.93, p<0.01) (21). A recent nationwide Swedish study incorporating more than 0.2 million men confirmed this reverse association (OR 0.80, 95\% CI 0.76-0.85) (22). Meanwhile, our group demonstrated that DM was associated with higher odds of detection of overall PC (OR 1.46, 95\% CI 1.06-2.01) more specifically high grade PC (OR 1.54, 95\% CI 1.03-2.29) via contemporary multi-core $(\geq 12)$ biopsy (23). Furthermore, our group reported that diabetics classified hemoglobin A1c less than 6.5\% had significantly higher rate of extraprostatic extension of tumor and high pathologic Gleason's score (10). Our recent study indicated that diabetics had short PSA doubling time after RP than non-diabetics during follow-up (24). A pooled analysis for long-term overall mortality showed DM is associated with higher risk (HR 1.57, 95\% CI 1.12-2.20) (25). Thus, we can plausibly predict that DM may have a protective effect against the development of PC, whereas pre-existing DM may lead to poor pathologic and oncologic outcomes. (26). 
Thus, DM could be one explanation for patients with low erectile function having adverse pathologic features in our study.

Metabolic syndrome, a cluster of risk factors of cardiovascular disease and DM, is a common medical condition in the United States and is present in one quarter of the population, with an incidence that increases with age (26). Although the definition may vary, metabolic syndrome typically consists of DM or impaired glucose tolerance, hypertension, dyslipidemia, and obesity, which generally overlap with the medical conditions discussed above. A population-based study in Finnish men demonstrated that metabolic syndrome was related to a higher risk of having PC (RR 1.9, 95\% CI 1.1-3.5) (27). Furthermore, a large matched case-control study reported from Vattikuti Urology Institute showed that metabolic syndrome men had higher Gleason grade $(p<0.001)$, higher pathologic stage $(p<0.001)$, and greater upgrading of Gleason grade $(p<0.001)$ (28).

As discussed earlier, many systemic conditions associated with ED also associateswith an aggressive PC biology. Thus, we hypothesize that these medical conditions have a common pathway of PC development or aggressive transformation. At the least, erectile function itself could be a surrogate barometer for PC aggressiveness. In the present study, we confirmed that patients who had severe ED (IIEF- $5<8$ ) had larger tumors and higher Gleason's scores even after adjusting for other factors. As mentioned, the etiology of ED itself is multifactorial and complicated, and thus, we cannot fully understand the exact mechanism of this phenomenon. However, it could be related to an altered hormonal milieu, such as testosterone or sex hormone-binding globulin (SHBG). Low testosterone which could lower erectile function was suggested to have poor prognostic factors and higher tumor volume (29). Low testosterone was also associated with extroprostatic disease (30).

Hypogonadism may make PC more aggressive; however, the reverse is also plausible. Several studies demonstrated that serum levels of total and free testosterone were significantly elevated after radical prostatectomy $(31,32)$.
Thus aggressive PC could be the possible cause of severe ED by inhibiting hypothalamic-pituitary axis. Our group previously reported the association between serum SHBG level with extraprostatic disease and higher Gleason score in clinically localized PC patients (33). Stimulation of cyclic adenosine monophosphate by the prostate was suggested as a possible mechanism. Significant role of SHBG in stem-like properties of PC has recently been demonstrated by cell lines study (34). SHBG was co-upregulated with related factors such as CD44, CD90, Oct3/4 and Nanog during progression. Furthermore, blocking SHBG gene rendered down regulation of theses stemness related factors. Higher SBHG expression in human PC specimens examined by immunohistochemistry is significantly associated with aggressive pathologic features (34). Thus, SHBG may involve with direct mechanism of cancer progression. Regarding obesity, adipose tissue itself has been regarded as an endocrine organ because it regulates multiple hormones via aromatase. Testosterone could be converted to estradiol by adipocytes and PC (35). This is strongly regarded as one mechanism of prostate carcinogenesis and tumor progression. Many adipokines such as leptin, interleukin-6, and adiponectin have been proved to have strong association with aggressive PC (36). The insulin/insulin-like growth factor-1 (IGF-1) axis is another commonly proposed mechanism. Poor glycemic control and hyperinsulinemia could lead to tumor aggressiveness. Chronically elevated glucose levels would lead to compensatory hyperinsulinemia. Insulin itself and IGF-1, which is regulated by insulin, promote proliferation and inhibit apoptosis in PC (37, 38). The DM-related micro-environment could be responsible for transformation to aggressive PC. Long-standing DM may cause vascular damage in both the prostate and corpus cavernosum, which is a contributing factor in the pathogenesis of benign prostatic hyperplasia and ED (39). Impaired circulation of the prostate also could induce tumor hypoxia, which may result in a more clinically aggressive tumor phenotype (40). Shared genetic susceptibility between obesity and diabetes mellitus with PC is also worth consideration. Genome wide studies showed at least 17 common 
obesity loci and 18 type 2 diabetes loci (41). PC related gene could overlap with these loci. Regarding dyslipidemia related mechanism, low high-density lipoprotein and high triglyceride levels also might be associated with high-grade PC (42). In vitro, triglycerides induce the proliferation of androgen-independent PC-3 cells.

The major limitation of the present study might be its retrospective nature in a single-center cohort. Furthermore, it may be subject to inherent biases during patient selection since 16\% $(272 / 1743)$ of the patients were excluded due to missing IIEF-5 results. Other limitations are the lacks of information about sex-hormone level, the cause of ED, and long-term follow-up outcomes. Nevertheless, our results provide new insight into the association between erectile function and PC pathophysiology. We believe our hypothesis deserves to be evaluated in a larger, multicenter cohort or in a prospective manner. We suggest that the future study should collect more specific information such as sex-hormone level or penile Doppler.

\section{CONCLUSIONS}

Lower erectile function before RP was significantly associated with some adverse pathologic outcomes, such as a higher Gleason score and larger tumor volume, even after adjusting for other variables. Thus, decreased erectile function could be a surrogate barometer for aggressive features of PC.

\section{ABBREVIATIONS}

$\mathrm{BMI}=$ body mass index

$\mathrm{CI}=$ confidence interval

$\mathrm{ED}=$ erectile dysfunction

$\mathrm{DM}=$ diabetes mellitus

$\mathrm{HR}=$ hazard ratio

IIEF-5 = the international index of erectile func-

tion-5

$\mathrm{LEF}=$ the low erectile function

$\mathrm{OR}=$ odds ratio

$\mathrm{PC}=$ prostate cancer

$\mathrm{RP}=$ radical prostatectomy

SEARCH $=$ Shared Equal Access Regional Cancer Hospital

\section{CONFLICT OF INTEREST}

None declared.

\section{REFERENCES}

1. Center MM, Jemal A, Lortet-Tieulent J, Ward E, Ferlay J, Brawley 0 , et al. International variation in prostate cancer incidence and mortality rates. Eur Urol. 2012;61:1079-92.

2. Kakehi Y. Active surveillance as a practical strategy to differentiate lethal and non-lethal prostate cancer subtypes. Asian J Androl. 2012;14:361-4.

3. Agarwal PK, Sadetsky N, Konety BR, Resnick MI, Carroll PR; Cancer of the Prostate Strategic Urological Research Endeavor (CaPSURE). Treatment failure after primary and salvage therapy for prostate cancer: likelihood, patterns of care, and outcomes. Cancer. 2008;112:307-14.

4. Alba FM, Wang R. Can erectile function be predicted after prostate câncer treatment? Asian J Androl. 2012;14:134-5.

5. Casey RG, Corcoran NM, Goldenberg SL. Quality of life issues in men undergoing androgen deprivation therapy: a review. Asian J Androl. 2012;14:226-31.

6. Mazzola CR, Mulhall JP. Impact of androgen deprivation therapy on sexual function. Asian J Androl. 2012;14:198203.

7. Lee RK, Chughtai B, Te AE, Kaplan SA. Sexual function in men with metabolic syndrome. Urol Clin North Am. 2012;39:53-62.

8. Shamloul R, Ghanem H. Erectile dysfunction. Lancet. 2013;381:153-65.

9. Freedland SJ, Bañez LL, Sun LL, Fitzsimons NJ, Moul JW. Obese men have higher-grade and larger tumors: an analysis of the duke prostate center database. Prostate Cancer Prostatic Dis. 2009;12:259-63.

10. Hong SK, Lee ST, Kim SS, Min KE, Byun SS, Cho SY, et al. Significance of preoperative $\mathrm{HbA1c}$ level in patients with diabetes mellitus and clinically localized prostate cancer. Prostate. 2009;69:820-6.

11. Lee SE, Lee WK, Jeong MS, Abdullajanov M, Kim DS, Park $\mathrm{HZ}$, et al. Is body mass index associated with pathological outcomes after radical prostatectomy in Korean men? BJU Int. 2011;107:1250-5.

12. Samaratunga H, Montironi R, True L, Epstein JI, Griffiths DF, Humphrey PA, et al. ISUP Prostate Cancer Group. International Society of Urological Pathology (ISUP) Consensus Conference on Handling and Staging of Radical Prostatectomy Specimens. Working group 1: specimen handling. Mod Pathol. 2011;24:6-15. 
13. van der Kwast TH, Amin MB, Billis A, Epstein JI, Griffiths D, Humphrey PA, et al. ISUP Prostate Cancer Group. International Society of Urological Pathology (ISUP) Consensus Conference on Handling and Staging of Radical Prostatectomy Specimens. Working group 2: T2 substaging and prostate cancer volume. Mod Pathol. 2011;24:16-25.

14. Lewis RW, Fugl-Meyer KS, Corona G, Hayes RD, Laumann EO, Moreira ED Jr, et al. Definitions/epidemiology/risk factors for sexual dysfunction. J Sex Med. 2010;7:1598-607.

15. Sakr WA, Haas GP, Cassin BF, Pontes JE, Crissman JD. The frequency of carcinoma and intraepithelial neoplasia of the prostate in young male patients. J Urol. 1993;150:379-85.

16. Haas GP, Delongchamps NB, Jones RF, Chandan V, Serio AM, Vickers AJ, et al. Needle biopsies on autopsy prostates: sensitivity of cancer detection based on true prevalence. J Natl Cancer Inst. 2007;99:1484-9.

17. Böhm M, Baumhäkel M, Teo K, Sleight P, Probstfield J, Gao P, et al. Erectile Dysfunction Substudy Investigators. Erectile dysfunction predicts cardiovascular events in highrisk patients receiving telmisartan, ramipril, or both: The ONgoing Telmisartan Alone and in combination with Ramipril Global Endpoint Trial/Telmisartan Randomized AssessmeNt Study in ACE iNtolerant subjects with cardiovascular Disease (ONTARGET/TRANSCEND) Trials. Circulation. 2010;121:1439-46.

18. Inman BA, Sauver JL, Jacobson DJ, McGree ME, Nehra A, Lieber MM, et al. A population-based, longitudinal study of erectile dysfunction and future coronary artery disease. Mayo Clin Proc. 2009;84:108-13.

19. Jayachandran J, Bañez LL, Aronson WJ, Terris MK, Presti JC $\mathrm{Jr}$, Amling CL, et al. SEARCH Database Study Group. Obesity as a predictor of adverse outcome across black and white race: results from the Shared Equal Access Regional Cancer Hospital (SEARCH) Database. Cancer. 2009;115:5263-71.

20. Shikata K, Ninomiya T, Kiyohara Y. Diabetes mellitus and cancer risk: review of the epidemiological evidence. Cancer Sci. 2013;104:9-14.

21. Kasper JS, Giovannucci E. A meta-analysis of diabetes mellitus and the risk of prostate cancer. Cancer Epidemiol Biomarkers Prev. 2006;15:2056-62.

22. Fall K, Garmo H, Gudbjörnsdottir S, Stattin P, Zethelius B. Diabetes mellitus and prostate cancer risk; a nationwide case-control study within PCBaSe Sweden. Cancer Epidemiol Biomarkers Prev. 2013;22:1102-9.

23. Hong SK, Oh JJ, Byun SS, Hwang SI, Lee HJ, Choe G, et al. Impact of diabetes mellitus on the detection of prostate cancer via contemporary multi $(\geq 12)$-core prostate biopsy. Prostate. 2012;72:51-7.

24. Oh JJ, Hong SK, Lee S, Sohn SJ, Lee SE. Diabetes mellitus is associated with short prostate-specific antigen doubling time after radical prostatectomy. Int Urol Nephrol. 2013;45:121-7.
25. Snyder CF, Stein KB, Barone BB, Peairs KS, Yeh HC, Derr $\mathrm{RL}$, et al. Does pre-existing diabetes affect prostate cancer prognosis? A systematic review. Prostate Cancer Prostatic Dis. 2010;13:58-64.

26. Ford ES, Giles WH, Dietz WH. Prevalence of the metabolic syndrome among US adults: findings from the third National Health and Nutrition Examination Survey. JAMA. 2002;287:356-9.

27. Laukkanen JA, Laaksonen DE, Niskanen L, Pukkala E, Hakkarainen A, Salonen JT. Metabolic syndrome and the risk of prostate cancer in Finnish men: a population-based study. Cancer Epidemiol Biomarkers Prev. 2004;13:164650.

28. Kheterpal E, Sammon JD, Diaz M, Bhandari A, Trinh QD, Pokala N, et al. Agarwal PK. Effect of metabolic syndrome on pathologic features of prostate cancer. Urol Oncol. 2013;31:1054-9.

29. García-Cruz E, Piqueras M, Huguet J, Peri L, Izquierdo L, Musquera M, et al. Low testosterone levels are related to poor prognosis factors in men with prostate cancer prior to treatment. BJU Int. 2012;110:E541-6.

30. Cabral PH, Iwamoto MW, Fanni VS, Barros Lda R, Cardoso SN, Mello LF, et al. Study of testosterone as a predictor of tumor aggressiveness in patients with prostate cancer. Int Braz J Urol. 2013;39:173-81.

31. Zhang PL, Rosen S, Veeramachaneni R, Kao J, DeWolf WC, Bubley G. Association between prostate cancer and serum testosterone levels. Prostate. 2002;53:179-82.

32. Miller LR, Partin AW, Chan DW, Bruzek DJ, Dobs AS, Epstein $\mathrm{Jl}$, et al. Influence of radical prostatectomy on serum hormone levels. J Urol. 1998;160:449-53.

33. Lee SE, Chung JS, Han BK, Park CS, Moon KH, Byun SS, et al. Preoperative serum sex hormone-binding globulin as a predictive marker for extraprostatic extension of tumor in patients with clinically localized prostate cancer. Eur Urol. 2008;54:1324-32.

34. Ma Y, Liang D, Liu J, Wen JG, Servoll E, Waaler G, et al. SHBG is an important factor in stemness induction of cells by DHT in vitro and associated with poor clinical features of prostate carcinomas. PLoS One. 2013;8:e70558.

35. Bonkhoff $H$, Berges R. The evolving role of oestrogens and their receptors in the development and progression of prostate cancer. Eur Urol. 2009;55:533-42.

36. Allott EH, Masko EM, Freedland SJ. Obesity and prostate cancer: weighing the evidence. Eur Urol. 2013;63:800-9.

37. Giovannucci E. Nutrition, insulin, insulin-like growth factors and cancer. Horm Metab Res. 2003;35:694-704.

38. Sarma AV, Jaffe CA, Schottenfeld D, Dunn R, Montie JE, Cooney KA, et al. Insulin-like growth factor-1, insulin-like growth factor binding protein-3, and body mass index: clinical correlates of prostate volume among Black men. Urology. 2002;59:362-7. 
39. Berger AP, Deibl M, Leonhartsberger N, Bektic J, Horninger W, Fritsche G, et al. Vascular damage as a risk fator for benign prostatic hyperplasia and erectile dysfunction. BJU Int. 2005;96:1073-8.

40. Jeong CW, Ku JH, Kwak C, Kim HH, Lee SE. Chronic pulmonary disease negatively influences the prognosis of patients with advanced prostate cancer. World J Urol. 2009;27:643-52.
41. Hofker M, Wijmenga C. A supersized list of obesity genes. Nat Genet. 2009;41:139-40.

42. Hayashi N, Matsushima M, Yamamoto T, Sasaki H, Takahashi $\mathrm{H}$, Egawa S. The impact of hypertriglyceridemia on prostate cancer development in patients aged $\geq 60$ years. BJU Int. 2012;109:515-9.

\section{Correspondence address:}

Sung Kyu Hong, M.D, Ph.D

Department of Urology

Seoul National University Bundang Hospital

82, Gumi-ro 173 Beon-gil, Bundang-gu, Seongnam Gyeonggi-do, 463-707, Korea

Fax: + 8231 787-4057

E-mail: skhong@snubh.org 